\title{
High-power inductive electric propulsion operation with alternative propellants
}

\author{
A. R. Chadwick* (iD B. Dally \\ ashley.chadwick@dlr.de \\ The University of Adelaide \\ School of Mechanical Engineering \\ Adelaide \\ Australia
}

\section{G. Herdrich}

The University of Stuttgart

Institute of Space Systems

Stuttgart

Germany

\section{Kim}

The University of Southampton

Department of Astronautics Research

Southampton

United Kingdom

\section{ABSTRACT}

This paper presents the results of an experimental campaign to measure thruster-relevant parameters for a high-power $(180 \mathrm{~kW})$ inductive propulsion system utilising $\mathrm{Ar}, \mathrm{O}_{2}, \mathrm{~N}_{2}$, and $\mathrm{CO}_{2}$ as propellants. Results from the investigation show that inductive thrusters can make use of these propellants without the severe degradation seen in other electric propulsion systems. Furthermore, the collection of experimental data at powers greater than $100 \mathrm{~kW}$ provides a reference of performance for the high-power electric propulsion devices intended for missions in the near future. Thrust and specific impulse in inductive systems can be improved by preferentially combining the chemical properties of atomic and molecular propellants. The maximum thrust recorded during these experiments was $7.9 \mathrm{~N}$, obtained using a combination of argon and oxygen $\left(0.68 \mathrm{Ar}+0.32 \mathrm{O}_{2}\right)$. The combination of argon and molecular propellants also decreased thermal losses within the discharge volume. Specific impulse can be doubled for the same input electric power by combining propellants, and future modifications to the thruster geometry and acceleration mechanism can be used to further improve the performance of such systems. 
Keywords: Electric propulsion; alternative propellants; inductive ; thrust

\section{NOMENCLATURE}

$\begin{array}{ll}c_{p, w} & \text { calorimeter water specific heat capacity, } \mathrm{kJ} / \mathrm{kg} . \mathrm{K} \\ e_{k i n} & \text { jet specific kinetic energy, } \mathrm{MJ} / \mathrm{kg} \\ F & \text { thrust, } \mathrm{N} \\ g_{0} & \text { standard gravity, } 9.81, \mathrm{~m} / \mathrm{s}^{2} \\ h_{j e t} & \text { jet specific enthalpy, } \mathrm{MJ} / \mathrm{kg} \\ I_{s p} & \text { specific impulse, } \mathrm{s} \\ j & \text { propellant flux, } 1 / \mathrm{s} \\ M & \text { molecular mass, } \mathrm{kg} / \mathrm{mol} \\ \dot{m} & \text { propellant mass flow rate, } \mathrm{kg} / \mathrm{s} \\ \dot{m}_{w} & \text { calorimeter water mass flow rate, } \mathrm{kg} / \mathrm{s} \\ n_{e} & \text { electron number density, } \mathrm{m}^{-3} \\ n_{n} & \text { neutral species number density, } \mathrm{m}^{-3} \\ P_{p l} & \text { jet calorimetric thermal power, } \mathrm{kW} \\ P_{R F} & \text { applied coil power, } \mathrm{kW} \\ \dot{Q}_{t u b e} & \text { Discharge tube heat flux, } \mathrm{kW} \\ u_{i} & \text { ionised species velocity, } \mathrm{m} / \mathrm{s} \\ u_{n} & \text { neutral species velocity, } \mathrm{m} / \mathrm{s} \\ \dot{V} & \text { propellant (normal) volumetric flow rate, } 1_{n} / \mathrm{min} \\ X_{S} & \text { molar fraction of species s }\end{array}$

\section{Greek Symbol}

$\Delta T_{w} \quad$ calorimeter water temperature difference, $\mathrm{K}$

$\Delta H_{f} \quad$ dissociation energy, $\mathrm{kJ} / \mathrm{mol}$

$\Delta H_{i} \quad$ ionisation energy, $\mathrm{kJ} / \mathrm{mol}$

$\eta_{F} \quad$ thrust efficiency

$\eta_{t h} \quad$ thermal efficiency

$\kappa \quad$ thermal conductivity, $\mathrm{kJ} / \mathrm{kg} . \mathrm{K}$

$\rho \quad$ density, $\mathrm{kg} / \mathrm{m}^{3}$

\subsection{INTRODUCTION}

For present space missions and operations, Earth represents the sole source of propellant within the solar system. The requirement to launch all necessary propellant with spacecraft from an Earth-based platform hence limits the range and duration achievable for a given mission. However, a number of locations within the solar system present resourcerich environments, with naturally occurring gas species $\left(\mathrm{O}_{2}, \mathrm{~N}_{2}, \mathrm{CO}_{2}\right)$ which may be used as propellants. These locations include asteroids, moons, and other planets such as Mars, each of which have been identified as targets for In-Situ Resource Utilisation (ISRU) ${ }^{(1-3)}$. The ability to utilise resources collected at these sites therefore presents a means to increase the maximum range, duration, and flexibility of space operations. 
Due to the high exhaust velocity produced by Electric Propulsion (EP) systems, in comparison to chemical propulsion, these systems are able to complete orbital transfers and manoeuvres with a reduced quantity of propellant. Combined with the high costs of conventional EP propellants, namely Xe, the prospect of using these naturally occurring gas species, termed alternative propellants, has motivated a number of numerical and experimental investigations $^{(4-16,19-22)}$.

This paper presents an overview on previous EP alternative propellant investigations, an assessment of limitations for the respective EP thruster classes, and recent thruster characterization measurements performed for a high-power inductive plasma generator. As will be shown, inductive EP systems are well-suited to the use of alternative propellants and have the potential to significantly influence the choice of propulsion for a given mission.

\subsection{PREVIOUS ALTERNATIVE PROPELLANT INVESTIGATIONS}

Table 1 lists previous investigations into the use of alternative propellants. These investigations have focused on applications from Atmosphere-Breathing Electric Propulsion $(\mathrm{ABEP})^{(6-10)}$ to long-duration cis-lunar trajectories ${ }^{(4)}$, and have considered a variety of conventional and advanced EP systems. Through these studies, the major factors affecting alternative propellant implementation are shown to be chemical compatibility, acceleration mechanism compatibility (relative to the conventional propellant), and scalability of the system.

The first and most fundamental restriction to operation with alternative propellants is that of chemical compatibility. During operation, EP systems are required to maintain nominal performance for periods in excess of $10,000 \mathrm{~h}^{(23,24)}$ without severe degradation of critical components. Ion thrusters, arcjets, and Magnetoplasmadynamic Thrusters (MPDT) showed significant electrode erosion when operated with chemically reactive alternative propellants $^{(7,12-15)}$. Thruster degradation was particularly observable when utilising oxygen, where each of these thruster classes suffered substantial damage to the electrodes over relatively short test times. For alternative propellants to be considered in these systems, significant improvements to the chemical resilience of thruster materials would be required. These improvements may come in the form of additional resistive coatings or a complete reselection of electrode material, though these changes will also heavily impact on the discharge conditions. Hall Effect Thrusters (HET) also showed significant degradation in some cases ${ }^{(7)}$. HET investigations in which no degradation was observed were also recorded ${ }^{(9,10)}$, though authors of these studies note that testing times were significantly lower than the thruster lifetime and that further testing would provide more substantial indicators of potential damage. Due to the direct contact between electrodes and plasma within these systems, it is likely they will also require significant material modifications. The most compatible systems tested were the helicon thrusters, which displayed no material degradation despite the presence of reactive species, such as oxygen and hydrogen. This compatibility is a result of the helicon thruster's electrodeless design, which separates the plasma and excitation mechanism (antenna) via a dielectric material.

The second critical issue is the compatibility of the alternative propellant with the thruster accelerations mechanism, which may be electrostatic, electromagnetic, or electrothermal, depending on the thruster. Alternative propellants must also be comparable to their conventional counterparts with respect to the total propulsion system mass and input 


\section{Table 1}

Overview of past studies of alternative propellants for electric propulsion

EP class

Electrostatic

Ion thruster

Hall effect

thruster

\section{Electromagnetic}

MPDT

\section{Electrothermal}

Arcjet

Helicon
Study

Dressler et al. $(2000)^{(5)}$

Nishiyama (2003) ${ }^{(6)}$

Cifali et al. $(2011)^{(7)}$

Frisbee et al. (1998) $)^{(4)}$

Cifali et al. $(2011)^{(7)}$

Pekker and Keidar (2012) ${ }^{(8)}$

Hohman (2012) $)^{(9)}$

Shabshelowitz (2013) $)^{(10)}$

Uematsu et al. (1984) $)^{(12)}$

Hou et al. (2011) $)^{(13)}$

Shiraki et al. $(2015)^{(14)}$

Yanagida et al. $(2015)^{(15)}$

Charles 2008 ${ }^{(16)}$

Nguyen et al. (2009) ${ }^{(17)}$

Shabshelowitz $(2013)^{(10)}$

Petro and Sedwick (2017) ${ }^{(18)}$
Propellant(s)

Iodine

Ar, $\mathrm{O}, \mathrm{O}_{2}, \mathrm{~N}_{2}, \mathrm{CO}_{2}$

$\mathrm{O}_{2}, \mathrm{~N}_{2}$

$\mathrm{O}_{2}$

$\mathrm{N}_{2}$, air

Air

$\mathrm{CO}_{2}$

$\mathrm{Ar}, \mathrm{N}_{2}$
Water

Water

Water

$\mathrm{N}_{2}, \mathrm{CH}_{4}, \mathrm{NH}_{3}$,

$\mathrm{N}_{2} \mathrm{O}$

Water

Ar, $\mathrm{N}_{2}$, air

Water

power requirements. Studies of ion thrusters showed theoretically superior exit velocities with alternative propellants owing to their lower molar mass ${ }^{(7)}$. However, in practice these systems suffered severe reductions in efficiency due to the increase in input power required to ionise the propellant species (in comparison to the conventional propellant, Xe). HET, MPDT, and arcjets showed performance within the same order of magnitude at that achievable using conventional propellants ${ }^{(7,9,10)}$. However, the aforementioned material limitations act to restrict the potential of such systems. Performance for the helicon sources was mixed. The Helicon Double Layer Thruster (HDLT) achieved specific impulses comparable to electrostatic devices ${ }^{(16)}$, while a conventional helicon source noted negligible improvement over cold gas specific impulse ${ }^{(10)}$. This shows that certain helicon sources may require additional acceleration mechanisms to meet the necessary thrust and velocity requirements.

The third major consideration is scalability of the system with respect to power. While the majority of the thrusters tested were small-scale $(<2 \mathrm{~kW})$, the theoretical mission analyses indicate the need for high-power EP systems to undertake the necessary trajectories and manoeuvres. This is supported by the missions currently being planned, some of which feature EP systems in excess of $10 \mathrm{~kW}^{(24,25)}$ or $100 \mathrm{~kW}^{(25)}$.

The sum of these considerations hence requires propulsion systems intended for operation with alternative propellants to exhibit high chemical compatibility, a robustness of plasma 
acceleration with respect to propellant chemical properties, and the ability to be scaled to high input powers. Using these criteria, a suitable candidate for alternative propellant EP is the Inductive Plasma Generator (IPG7) developed at the Institute of Space Systems (IRS) ${ }^{(26,27)}$. This system, originally developed for experimental atmospheric entry simulation, uses an electrodeless mechanism to heat its medium and operates at a maximum power of $180 \mathrm{~kW}$. This paper will report on the results of an experimental investigation into thruster performance with a variety of propellants and provide an assessment of how future design iterations may further improve the thrust and specific impulse produced.

\subsection{EXPERIMENTAL SETUP}

Originally designed for experimental re-entry simulation ${ }^{(26)}$, the inductive plasma generator systems developed at IRS are compatible with a wide variety of gas species, including highly reactive species such as $\mathrm{O}_{2}$. IPG7 is the latest iteration of this class of plasma generator, with the experimental facility used for these tests shown in Fig. 1.

At this facility, the IPG7 is capable of sustained operation at powers up to $180 \mathrm{~kW}$ for durations in excess of $30 \mathrm{~min}$. Electrical input power is supplied from the source triode to the inductive coil, with a resonant circuit used to minimise reflected power. The supply circuit includes a capacitor bank with seven $6 \mathrm{nF}( \pm 20 \%)$ capacitors, used to set the coil driving frequency between 0.5 and $1.5 \mathrm{MHz}$. The number of coil turns can also be used to change the driving frequency ${ }^{(26,28)}$, though for these experiments a single 5.5 turn coil geometry was used. The number of capacitors was also fixed at 5 , resulting in a baseline driving frequency of $586 \mathrm{kHz}$.

The discharge chamber (tube) of the IPG7 is $285 \mathrm{~mm}$ long, with an outer diameter of $90 \mathrm{~mm}$ $( \pm 0.2 \mathrm{~mm})$ and a tube wall thickness of $2.2 \mathrm{~mm}( \pm 0.2 \mathrm{~mm})$. The vacuum chamber used within these experiments has a length of $3 \mathrm{~m}$ and diameter of $2 \mathrm{~m}$. This chamber is connected to the IRS main vacuum facility, capable of extracting $150,000 \mathrm{~m}^{3} / \mathrm{h}$ of air at atmospheric conditions and $250,000 \mathrm{~m}^{3} / \mathrm{h}$ at pressures below $10 \mathrm{~Pa}$. Without propellant flow, the test facility can be evacuated to ambient pressures of $1 \mathrm{~Pa}$. Due to the thruster geometry and high-power nature of the facility, tests using the IPG7 require propellant flow rates of $50-3001_{n} / \mathrm{min}(1-6.5 \mathrm{~g} / \mathrm{s})$, resulting in ambient chamber pressures of $10-30 \mathrm{~Pa}$ during operation and thruster discharge pressures of 500-2000 Pa. While this is a relatively high ambient pressure range for thrustspecific applications, the facility requires such flow rates to match the geometry scale of the thruster. As previously mentioned, the IPG7 was originally designed for re-entry simulation and as such is by no means optimised for thrust generation. The focus of this study is to assess and quantify the behaviour of alternative propellants under fixed conditions, rather than qualify the thruster itself for operation used. As a result, this high ambient pressure is deemed acceptable, with knowledge gained being actively utilised in a separate, thruster development-focused arm of research at IRS ${ }^{(29)}$. Potential propellant re-ingestion due to the presence of a measurement probe, thrust or otherwise, was investigated using a Hofer-Noser Karrer $(\mathrm{HOKA})^{(30)}$ probe. This highly sensitive $( \pm 1.5 \%)$ device was used to measure the discharge coil current and its interaction with charged heavy particles within the discharge volume. Measurements were first taken under free outflow conditions, with no probes or obstructions between the thruster exit and vacuum facility, and then compared with values recorded during intrusive probe measurements. For the investigation conducted, no significant deviations, within the measurement accuracy of the device, were observed. As such, re-ingestion was deemed negligible. As with the chamber ambient pressure, re-ingestion is 

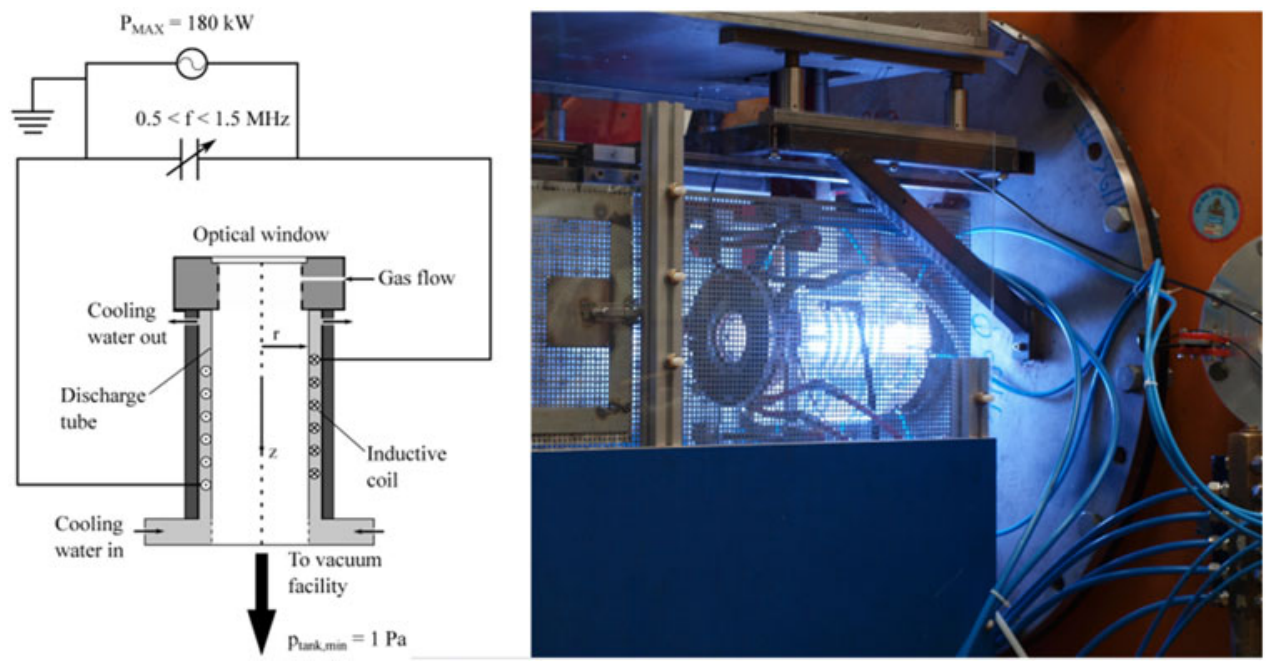

Figure 1. IPG7 schematic layout (left) ${ }^{(30)}$ and during operation with argon (right).
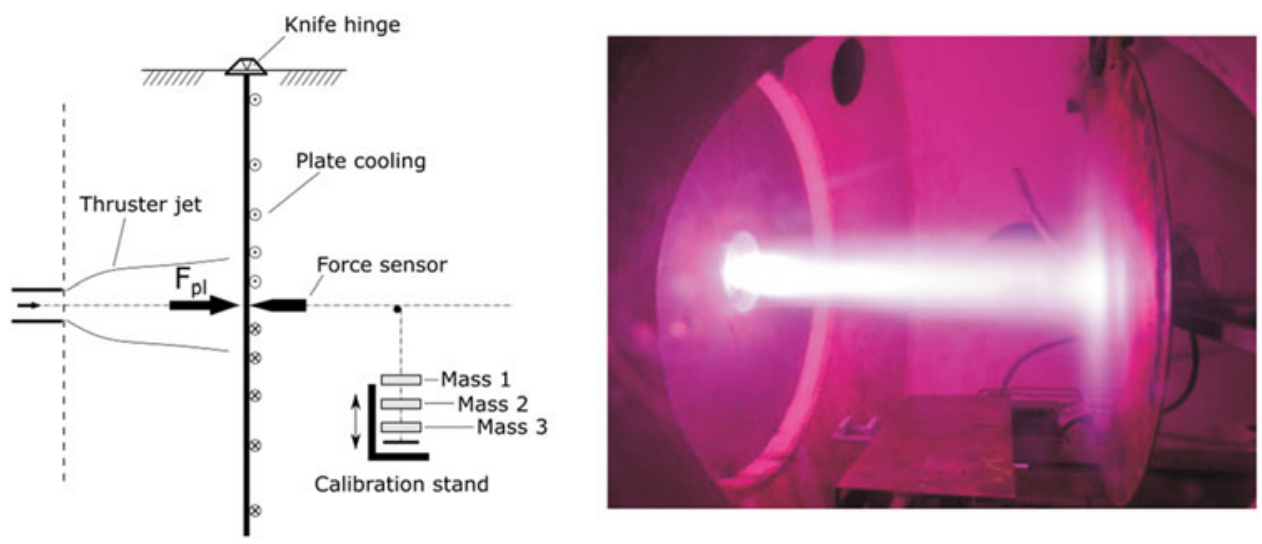

Figure 2. Baffle plate schematic layout (left) and during operation with hydrogen (right) ${ }^{(28)}$.

of greater interest in assessing the design and development of the thruster itself rather than the propellants utilised. These topics will be investigated in greater detail for subsequent generations of inductive thruster.

During this investigation, thrust measurements were obtained using a baffle plate arrangement $^{(28)}$, shown in Fig. 2. This baffle plate is constructed as a grounded, water-cooled target suspended on knife hinges at a distance of $1.30 \mathrm{~m}$ from the thruster exit. A MEMesssysteme KD40s force sensor was used to measure thrust produced by the IPG7 jet, with the diameter of the plate $(1.25 \mathrm{~m})$ being large enough to capture the full propellant flow. Using a dynamic calibration stand consisting of three distinct masses $(0.151,0.149$, and $0.145 \mathrm{~kg})$, the force sensor can be calibrated (by means of linear extrapolation) before each test. The major source of errors using the baffle plate result from noise generated by the plate cooling water, used to sustain the high heat loading incident on the copper plate during operation. This results in a measurement error of $\pm 0.73 \mathrm{~N}\left(<10 \% \mathrm{~F}_{\max }\right)$. During cold gas test condition 


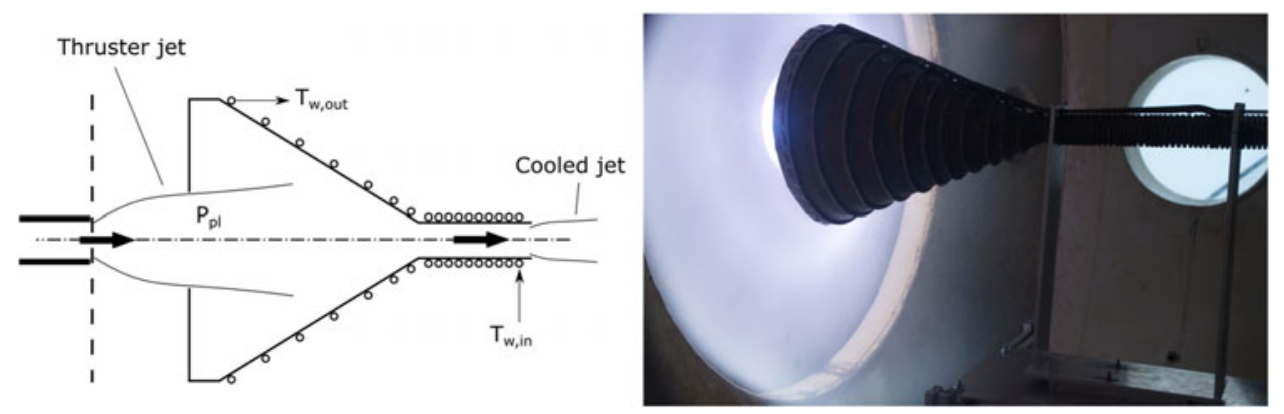

Figure 3. Cavity calorimeter during operation.

(requiring no water), the baffle plate has been measured to show a $\pm 0.27 \mathrm{~N}$ agreement with a pendulum thrust balance ${ }^{(28)}$.

Using the thrust measurement from the baffle plate, the jet specific impulse $\left(\mathrm{I}_{s p}\right)$ and thrust efficiency $\left(\eta_{F}\right)$ can be calculated using:

$$
\begin{gathered}
I_{s p}=\frac{F}{g_{0} \dot{m}}, \\
\eta_{F}=\frac{F^{2}}{2 \dot{m} P_{R F}},
\end{gathered}
$$

where $F$ is the measured thrust, $g_{0}$ is standard gravity, $\dot{m}$ is the propellant mass flow rate, and $P_{R F}$ is the input power to the thruster. This value is $75 \%$ of the anode power due to inherent triode losses ${ }^{(31)}$, which can be removed with the choice of a more modern power supply.

Jet specific enthalpy $\left(\mathrm{h}_{j e t}\right)$ was determined using a cavity calorimeter ${ }^{(26)}$, shown in Fig. 3, and the relation:

$$
h_{j e t}=\frac{P_{p l}}{\dot{m}}=\frac{c_{p, w} \dot{m}_{w} \Delta T_{w}}{\dot{m}},
$$

where $\mathrm{P}_{p l}$ is the thermal power measured by the calorimeter, and $\mathrm{c}_{p, w}, \dot{m}_{w}$, and $\Delta T_{w}$ are the specific heat capacity, mass flow rate, and temperature increment of water flowing through the calorimeter structure. The calorimeter inlet diameter is $125 \mathrm{~mm}$, placed $110 \mathrm{~mm}$ downstream of the thruster outlet in order to capture the full plasma flow and not interfere with the inductive coil by proximity. Once within the calorimeter chamber, thermal energy is extracted from plasma via the water-cooled copper body. The difference in cooling water temperature, combined with the water flow rate, is used to calculate the thermal power of the flow. Values of heat flux within the discharge tube, $\dot{Q}_{t u b e}$, are determined using the same calorimetric method, using information on the inflow and outflow coolant temperatures as well as the coolant flow rate. In calculating values of $\mathrm{P}_{p l}$ and $\dot{Q}_{t u b e}$, uncertainties in the cooling water mass flow rate and measured temperature are typically less than $1 \%$. Uncertainties are hence dominated by the stability and duration of the discharge mode at a given input power, which has been explored in previous works ${ }^{(30)}$.

Measurements from both the baffle plate and cavity calorimeter were only recorded once steady state, thermal equilibrium conditions had been achieved. Due to the separation of working fluid and excitation mechanism via the dielectric discharge chamber, negligible variation 
in both thrust and jet power measurements $(\approx 1 \%)$ were observed in this facility. Only gradual degradation of the triode anode (over the course of several years of testing) produces significant change in recorded values. This degradation is monitored by facility staff and the anode replaced once inaccuracies exceed a $2 \%$ limit. As a result, the primary source of measurement errors in this study were those resulting from cooling water noise, as previously discussed.

For this investigation, four candidate propellants were identified. These are argon, oxygen, nitrogen, and $\mathrm{CO}_{2}$. Argon was selected due to its similarity to the conventional propellant xenon. Both enter the discharge volume as an atomic gas, reducing the potential energy modes exhibited by the resultant plasma. Oxygen and nitrogen were selected in order to provide two candidate propellants exhibiting a diatomic structure. This allows comparisons to the monatomic argon as well to each other, given their respective dissociation and ionisation energies. These two gases are abundant within the solar system, constituting the primary atmospheric components of several large bodies such as Earth ${ }^{(32)}$ and Titan ${ }^{(33)}$. In addition, oxygen may be extracted in significant quantities by processing stores of water found on asteroids and other icy bodies ${ }^{(34,35)}$. Finally, $\mathrm{CO}_{2}$ was chosen as the polyatomic propellant candidate, allowing knowledge gained from oxygen experiments to be built upon. $\mathrm{CO}_{2}$ also represents an attractive propellant choice; it is both a significant waste component in spacecraft Environmental Control and Life Support Systems (ECLSS) ${ }^{(36)}$ and is the primary atmospheric component on Mars ${ }^{(37)}$ and Venus ${ }^{(38)}$.

\subsection{EXPERIMENTAL RESULTS}

Table 2 lists the volumetric mixture ratios, effective mass flow rates, and recorded cold gas thrust values of the propellant conditions investigated. Information on the volumetric flow rate and particle flux of each propellant configuration tested is given in the appendices of this paper. The propellant molar fractions and mass flow rates were varied in order to enable comparisons on volumetric, mass, and particle flux bases.

Figures 4 through 6 show values of thrust, $\mathrm{I}_{s p}$, and thrust-to-power ratio $\left(\mathrm{F} / \mathrm{P}_{R F}\right)$ for pure argon, oxygen, nitrogen, and $\mathrm{CO}_{2}$ plasmas, as well as plasmas resulting from combinations of argon and the molecular species.

As shown in Figs 4 through 6, propellant configurations combining argon and the other gases produced significant increases in measured thrust, $\mathrm{I}_{s p}$, and $\mathrm{F} / \mathrm{P}_{R F}$ over their pure gas counterparts, with the exception of oxygen which displayed a slight reduction of $\mathrm{I}_{s p}$. The reason for this general increase in thrust-specific performance, as well as the difference between final values obtained by the single propellants, is thought to be a result of the propellant chemical properties and the discharge regime of the resultant plasma.

At low input powers, heating in the discharge chamber is low due to the low coupling efficiency of the capacitive mode ${ }^{(26,30)}$. As a result, propellants exhibit similar values of $\mathrm{I}_{s p}$ $(\approx 50 \mathrm{~s})$ at zero input power conditions and similar thrust for input powers below $20 \mathrm{~kW}$. At higher input powers, the influence of $\mathrm{I}_{s p}$ dominates that of the mass flow rate.

The final velocity of particles exiting the thruster is dependent on the species molecular mass. With the exception of $\mathrm{CO}_{2}$, Ar has the highest molecular mass, with the other propellants able to obtain greater exit velocities in their molecular states. The impact of molecular mass on velocity is further highlighted when considering dissociation of the propellants. Any dissociation of $\mathrm{O}_{2}, \mathrm{~N}_{2}$, or $\mathrm{CO}_{2}$ greatly increases the maximum obtainable value of $\mathrm{I}_{s p}$ in comparison to Ar. In the combined cases, dissociation acts to significantly lower the mean species molecular mass, as shown in Fig. 7. 
Table 2

Mixed propellant chemistry (by volume), effective mass flow rate, and cold gas thrust

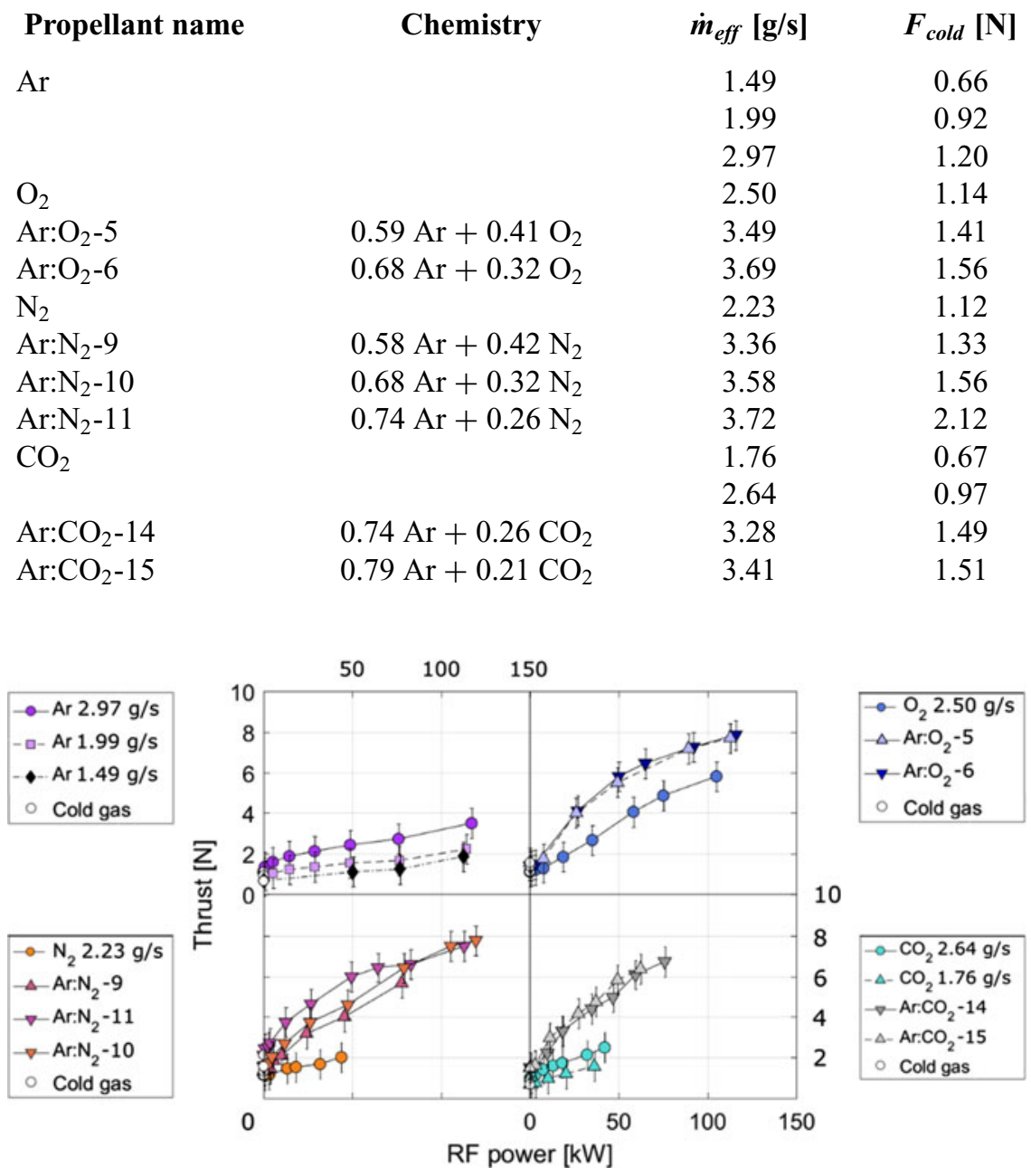

Figure 4. Measured alternative propellant thrust at respective mass flow rates (Table 2) and thruster input (RF) power.

However, as is seen in Figs 4 through 6, the molecular propellants produced higher thrust when combined with Ar, despite the increase in mean molecular mass. The increase of thrust is also greater than that which can be attributed to the propellant mass flow rate. Thrust values recorded for $\mathrm{N}_{2}$ and $\mathrm{CO}_{2}$ were each a factor of 2 higher for $50 \%$ and $20 \%$ increases in the total mass flow rate, respectively. This improved performance is a result of an increased translational temperature in discharge volume.

Increasing translational temperature acts to increase the pressure in the discharge chamber and causes propellant to exit the thruster at higher velocities. As the IPG7 is an electrothermal thruster, without additional acceleration mechanisms, the pressure difference between the 


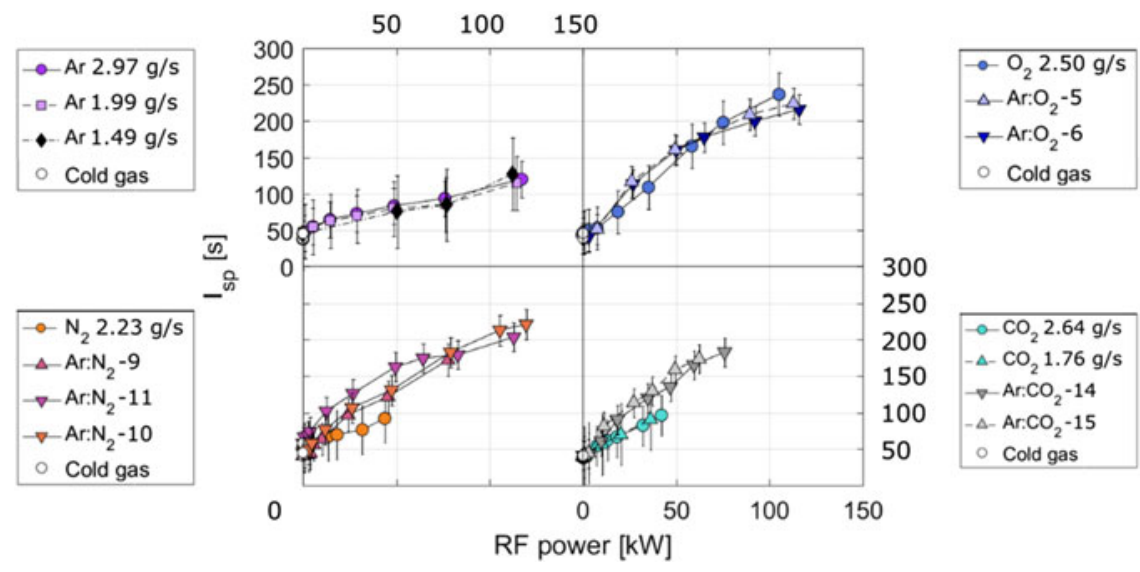

Figure 5. Alternative propellant specific impulse (conditions as in Fig. 4).

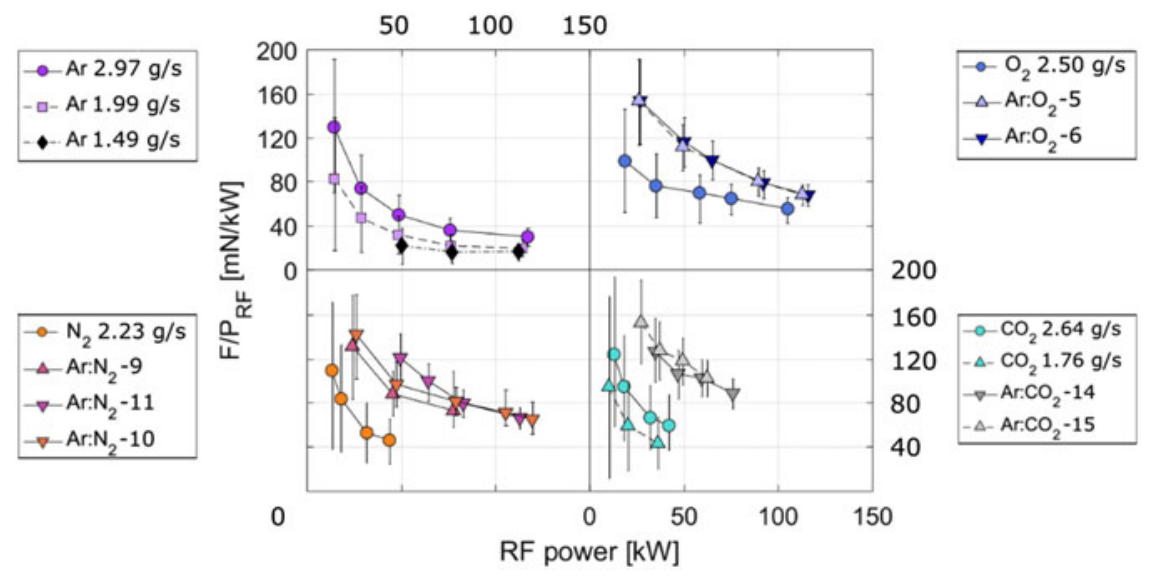

Figure 6. Alternative propellant thrust-to-power ratio (conditions as in Fig. 4).

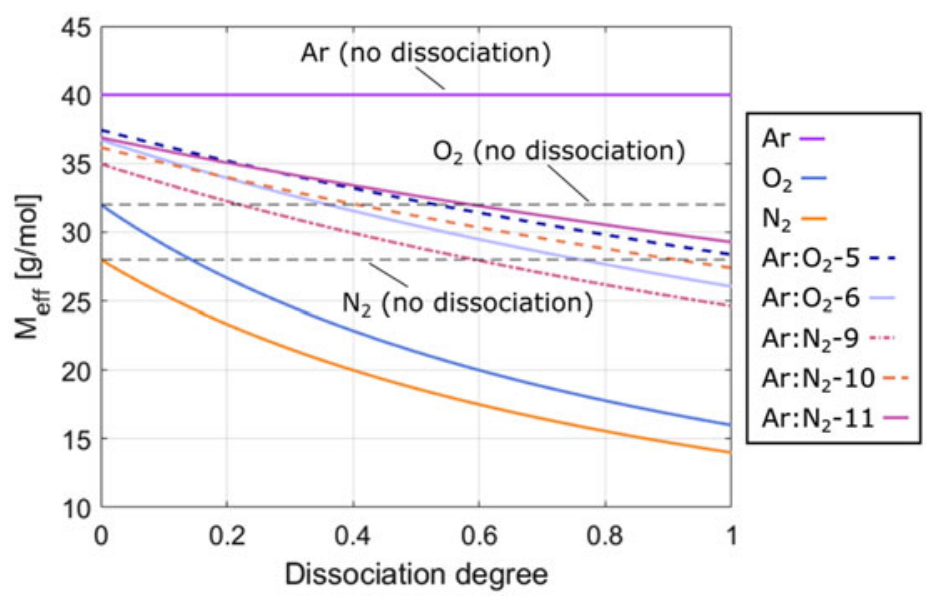

Figure 7. Impact of of propellant dissociation on mean molecular mass. 
discharge volume and vacuum tank is the sole source of propellant acceleration. Due to the high discharge pressures and low magnetic field strength of the inductive coil, acceleration from electromagnetic forces can be neglected from analyses of thrust production. Translational temperature in the IPG7 jet is dependent on two primary factors; the quantity of energy transferred from the inductive coil and its distribution among heavy particles in the plasma.

Within electrodeless thrusters, energy is transferred from the coil to the electrons, which in turn transfer energy to heavy particles as a result of collisional (Ohmic) heating. The magnitude of energy conveyed to the propellant is dependent on the electron number density within the discharge volume, requiring consideration of the ionisation energy of the propellant species. Of the propellants tested, Ar yields the highest electron number density per unit of input power. This is due to its atomic structure, with incoming energy converted to either excitation or ionisation processes. By comparison, molecular propellants are subject to additional losses such as dissociation and the rotational and vibrational energy modes. However, despite its affinity for ion and electron production, final $\mathrm{I}_{s p}$ values recorded for Ar were almost a factor of 2 lower than propellant mixtures of significantly higher net ionisation energy. This is thought to be due to the second factor influencing translational temperature in the discharge volume; the thermal conductivity of the plasma.

As thrust is produced by heavy particle species (neutral and ionised) in the IPG7, the transfer of energy between atoms and molecules within the discharge volume is of high importance. Observing the thermal conductivities of the propellants investigated (see Appendix), the low value of Ar for both thermal conductivity and specific heat capacity explain why pure Ar propellants were ineffective at converting power from the inductive coil to useful thrust. This conversion was more effective for the molecular species, each of which exhibit higher specific heat capacity and gas thermal conductivity (with the exception of $\mathrm{CO}_{2}$ for which thermal conductivity is lower than Ar at room temperature). A numerical investigation to assess the thermochemical state of the discharge and provide greater insight into these results is presently underway. However, due to the size of undertaking for such an investigation, results cannot be included in this paper.

The combination of these factors, being the molecular mass of the propellant, the transfer of energy from the inductive coil to electrons, and the distribution of thermal energy in the discharge, can be used to explain the results shown in Figs 4 through 6.

$\mathrm{O}_{2}$ displayed the highest final thrust, $\mathrm{I}_{s p}$, and $\mathrm{F} / \mathrm{P}_{R F}$ from the molecular propellants as a result of its comparably low dissociation and ionisation energies, as well as its high thermal conductivity and specific heat capacity. Both $\mathrm{N}_{2}$ and $\mathrm{CO}_{2}$ displayed poor performance due to their respective chemical properties. The high ionisation energy, dissociation energy, and specific heat capacity of these two propellants resulted in a high temperature, yet lowly ionised, gas. As a result, $\mathrm{N}_{2}$ and $\mathrm{CO}_{2}$ exerted significant thermal stress on the discharge tube at relatively low input powers $(<50 \mathrm{~kW})$. This prevented additional power to be applied to the propellant without the risk of critical damage to the thruster. The discharge tube heat fluxes recorded during experiments are shown in Fig. 8.

The increased thrust, $\mathrm{I}_{s p}$, and $\mathrm{F} / \mathrm{P}_{R F}$ of the propellant mixtures is a result of preferential combination of propellant chemical properties. By combining argon with the molecular species, argon's affinity to produce a high discharge electron number density was combined with the high thermal conductivity and low molecular mass of the other gases. This facilitated an effective transfer of energy from the coil to heavy particles in the discharge volume and hence a high thruster performance. Furthermore, the combined thermal conductivity of these 


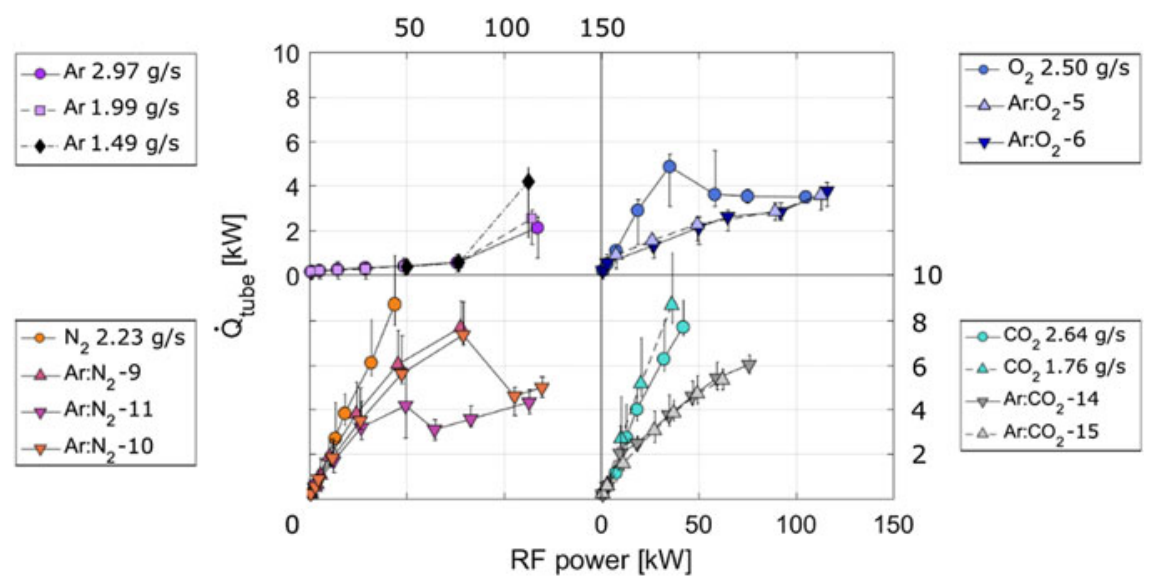

Figure 8. Discharge tube heat flux for the alternative propellants (conditions as in Fig. 4).

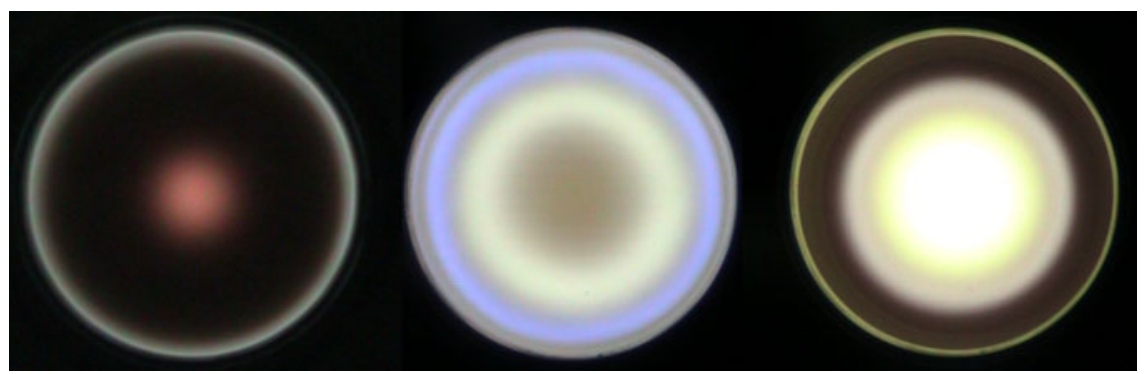

Figure 9. Capacitive (left), low inductive (centre), and high inductive (right) discharge cross-sections for $\mathrm{O}_{2}{ }^{(30)}$.

propellant mixtures acted to reduce thermal loads on the discharge chamber, allowing $\mathrm{N}_{2}$ and $\mathrm{CO}_{2}$ to be used with higher input powers.

Decreases in discharge tube heat flux for increasing input power, as shown in Fig. 8 for the $\mathrm{O}_{2}$ and Ar: $\mathrm{N}_{2}$ conditions, highlight another critical factor when considering the performance of propellants within the thruster. This behaviour is representative of the high inductive discharge regime, with the plasma condensing about the discharge chamber axis (and hence increasing the thermal boundary layer within the tube $)^{(26,30)}$. Inductively coupled plasma generators display a number of discharge regimes ${ }^{(26,44)}$. These include the capacitive regime and numerous stable (and unstable) inductive regimes, with each regime exhibiting a distinctive electromagnetic field orientation and plasma-coil coupling efficiency. The IPG7 is known to display three distinct stable discharge regimes, being capacitive, low inductive, and high inductive ${ }^{(30)}$. Examples of the discharge cross-sections of these three regimes are shown in Fig. 9. Energy coupling between the coil and plasma is lowest for the capacitive regime, increases through the low inductive regime, and reaches a maximum in the high inductive regime $^{(30)}$. Increased coupling efficiency hence leads to a greater proportion of electrical input energy being transferred to the propellant. As can be seen from the results presented in this paper, this has a significant effect on final values of thrust and $\mathrm{I}_{s p}$ produced by the thruster. 
Table 3

Maximum performance conditions of the propellants tested

\begin{tabular}{|c|c|c|c|c|c|c|}
\hline Propellant & $\begin{array}{c}\dot{m} \\
{[g / s]}\end{array}$ & $\begin{array}{c}\mathbf{F}_{M A X} \\
{[\mathbf{N}]}\end{array}$ & $\begin{array}{c}\mathbf{I}_{s p, M A X} \\
{[\mathbf{s}]}\end{array}$ & $\begin{array}{c}\mathbf{P}_{R F} \\
{[\mathbf{k W ]}}\end{array}$ & $\begin{array}{c}\eta_{F} \\
{[\%]}\end{array}$ & $\begin{array}{c}\mathbf{F} / \mathbf{P}_{R F} \\
{[\mathrm{mN} / \mathbf{k W}]}\end{array}$ \\
\hline $\mathrm{O}_{2}$ & 2.50 & 5.8 & 236.7 & 105 & 6.4 & 55.4 \\
\hline Ar: $\mathrm{O}_{2}-5$ & 3.49 & 7.7 & 224.2 & 113 & 7.5 & 68.3 \\
\hline Ar: $\mathrm{O}_{2}-6$ & 3.69 & 7.9 & 216.1 & 116 & 7.3 & 67.8 \\
\hline $\mathrm{N}_{2}$ & 2.23 & 2.0 & 91.7 & 44 & 2.0 & 45.9 \\
\hline $\mathrm{Ar}: \mathrm{N}_{2}-9$ & 3.36 & 5.7 & 172.3 & 78 & 6.2 & 72.8 \\
\hline Ar: $N_{2}-10$ & 3.58 & 7.8 & 221.4 & 120 & 7.1 & 65.0 \\
\hline Ar: $N_{2}-11$ & 3.72 & 7.5 & 203.8 & 113 & 6.7 & 66.3 \\
\hline $\mathrm{CO}_{2}$ & 2.64 & 2.5 & 96.1 & 42 & 2.8 & 59.3 \\
\hline $\mathrm{Ar}: \mathrm{CO}_{2}-14$ & 3.28 & 6.7 & 183.3 & 76 & 9.0 & 88.7 \\
\hline $\mathrm{Ar}: \mathrm{CO}_{2}-15$ & 3.41 & 6.4 & 173.8 & 62 & 9.7 & 102.3 \\
\hline
\end{tabular}

Table 4

Comparative performance of other EP systems with alternative propellants

$\begin{array}{lcccccc}\begin{array}{l}\text { Propellant/ } \\ \text { Thruster }\end{array} & \begin{array}{c}\dot{\boldsymbol{m}} \\ {[\mathbf{g} / \mathbf{s}]}\end{array} & \begin{array}{c}\mathbf{F}_{\boldsymbol{M A X}} \\ {[\mathbf{N}]}\end{array} & \begin{array}{c}\mathbf{I}_{\boldsymbol{s} \boldsymbol{p}, \boldsymbol{M A X} \boldsymbol{X}} \\ {[\mathbf{s}]}\end{array} & \begin{array}{c}\mathbf{P} \\ {[\mathbf{k W}]}\end{array} & \begin{array}{c}\boldsymbol{\eta}_{\boldsymbol{F}} \\ {[\%]}\end{array} & \begin{array}{c}\mathbf{F} / \mathbf{P} \\ {[\mathbf{m N} / \mathbf{k W}]}\end{array} \\ \mathrm{O}_{2} & & & & & & \\ \mathrm{RIT}[7] & 2.03 \times 10^{-4} & 6.00 \times 10^{-3} & 3016 & 0.45 & 19.7 & 13.3 \\ \mathrm{~N}_{2} & & & & & & \\ \mathrm{RIT}^{(7)} & 1.77 \times 10^{-4} & 5.25 \times 10^{-3} & 3017 & 0.45 & 17.3 & 11.7 \\ \mathrm{HET}^{(7)} & 2.27 \times 10^{-3} & 21.0 \times 10^{-3} & 944 & 1.06 & 9.2 & 23.6 \\ \mathrm{HHT}^{(10)} & 4.86 \times 10^{-3} & 39.0 \times 10^{-3} & 818 & 1.86 & 8.4 & 21.0 \\ \mathrm{CO}_{2} & & & & & & \\ \mathrm{HET}^{(9)} & 3.95 \times 10^{-4} & 3.25 \times 10^{-3} & 838 & 1.50 & 0.9 & 21.7\end{array}$

\subsection{Thruster Comparison with Alternative Propellants}

Table 3 shows the maximum thrust and $\mathrm{I}_{s p}$ conditions obtained for $\mathrm{O}_{2}, \mathrm{CO}_{2}, \mathrm{~N}_{2}$, and their combinations with argon, including their respective input powers and thrust efficiencies. The performance of conventional EP systems using the same propellants is tabulated in Table 4. As can be seen, values for thrust efficiency and $\mathrm{F} / \mathrm{P}_{R F}$ recorded for IPG7 are comparable to the conventional thrusters. However, values for $\mathrm{I}_{s p}$ are up to a factor of 10 lower than those achievable with ion thrusters. The highest $\mathrm{I}_{s p}$ recorded in this work $\left(236.7 \mathrm{~s}\right.$ for $\left.\mathrm{O}_{2}\right)$ is still well below the $350 \mathrm{~s}$ value used to justify the use of EP over classical chemical propulsion. However, given the present, basic design of the IPG7, a number of possibilities exist to improve values of $\mathrm{I}_{s p}$ to a competitive level. Combined with the system's high thrust and thrust-to-power ratio, the potential for inductive propulsion systems to play a key role in future space operations is high.

The primary limitation to propellant exhaust velocity in this system can be described in terms of the suboptimal thruster geometry. While the electrothermal mechanism generates thrust through heating of the working fluid, the constant cross-section of the IPG7 provides no preferential expansion (and hence acceleration) of the gas. This reduces the maximum thruster 

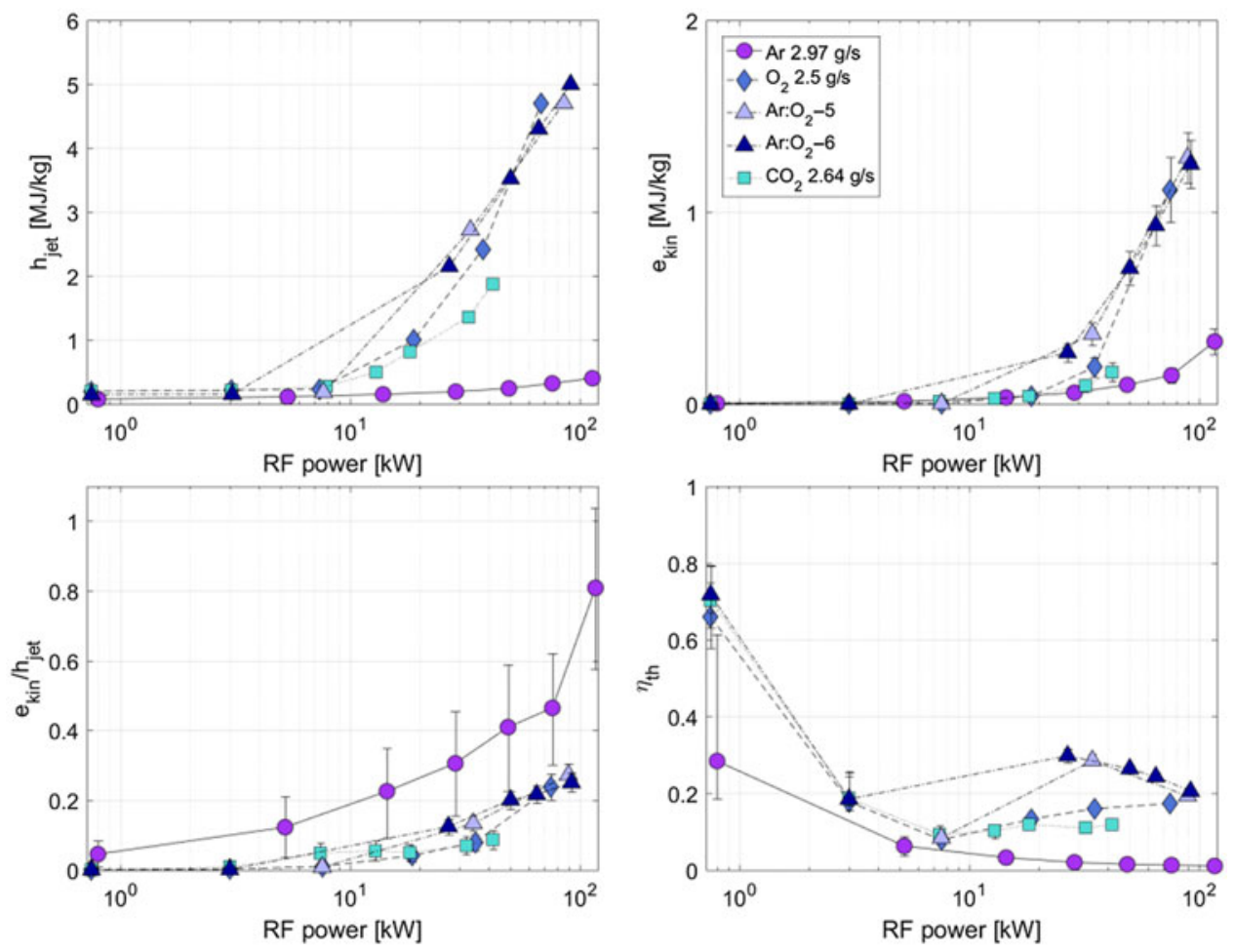

Figure 10. Comparison of jet specific enthalpy, specific kinetic energy, and thruster thermal efficiency for IPG7.

$\mathrm{I}_{s p}$ in comparison to other electrothermal EP classes such as arcjets, which use a nozzle to accelerate flow from the discharge volume. As a result, the implementation of a mechanical nozzle should provide significant additional jet velocity through dedicated expansion and acceleration of the flow.

Figure 10 shows values for the jet specific enthalpy, specific kinetic energy $\left(e_{k i n}=\right.$ $\left.\frac{1}{2}(F / \dot{m})^{2}-e_{k i n, c o l d}\right)$, and thermal efficiency $\left(\eta_{t h}=P_{p l} / P_{R F}\right)$ for $\mathrm{Ar}, \mathrm{O}_{2}, \mathrm{CO}_{2}$, and the Ar: $\mathrm{O}_{2}$ mixtures. With the exception of Ar, the propellants display common trends in jet enthalpy and kinetic energy, tending towards a $25 \%$ conversion of enthalpy to usable kinetic energy. The higher ratio for the Ar case is a result of direct transfer of electrical to thermal energy due to the absence of molecular loss mechanisms. The conversion of electrical power to jet thermal power also displays convergence towards a value of $20 \%$. Through the use of a nozzle, the kinetic energy of the flow can be increased. Values of $\eta_{t h}$ are dependent on the geometry of the discharge volume with respect to the inductive coil, and hence modifications to these values would require more extensive modifications to the thruster design.

Another method of increasing the specific impulse is to apply an external, electromagnetic or electrostatic acceleration mechanism to the flow, thus increasing the charged heavy particle velocity to levels comparable with other EP systems. However, developed originally as a tool for planetary entry simulation, the primary focus of the IPG7 is to produce flows of high enthalpy rather than a significant degree of ionisation. Previous studies have estimated this degree of ionisation as less than $10 \%{ }^{(45,46)}$. This limits the impact of charged species on the effective average thruster impulse. Figure 11 shows the effective (mean) specific impulse with 


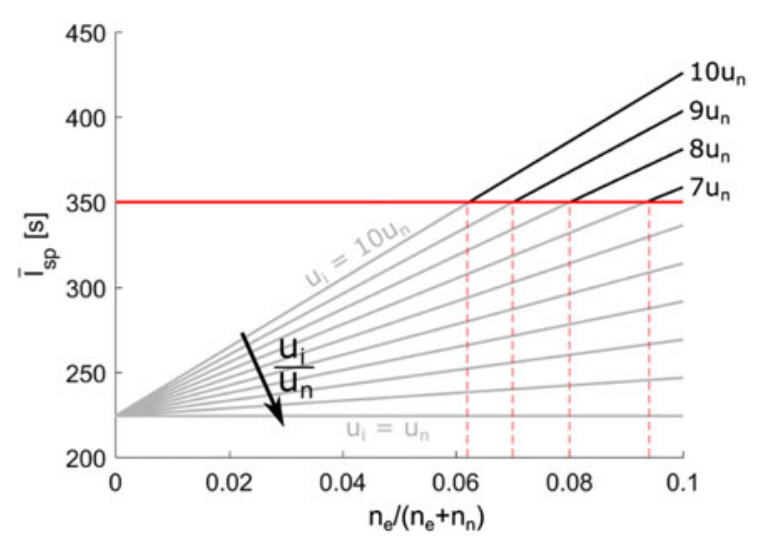

Figure 11. Effective average thruster exhaust velocity after charged particle acceleration.

respect to flow ionisation degree $\left(n_{e} /\left(n_{e}+n_{n}\right)\right)$ for a number of charged particle acceleration gains, calculated as:

$$
\bar{I}_{s p}=\frac{1}{g_{0}}\left(u_{i}\left(\frac{n_{e}}{n_{e}+n_{n}}\right)+u_{n}\left(1-\frac{n_{e}}{n_{e}+n_{n}}\right)\right),
$$

where $u_{i}$ and $u_{n}$ are the ion and neutral exhaust velocities, respectively. The baseline value for $\mathrm{u}_{n}$ is taken from the $\mathrm{Ar}: \mathrm{O}_{2}-5$ as a reference.

Accelerating charged heavy species to 10 times the neutral species velocity would provide the necessary mean propellant velocity for $n_{e} /\left(n_{e}+n_{n}\right)>6 \%$. While this is a feasible ionisation degree for present IPG7 operation, the flux of propellant through this system is significantly larger than that of present electrostatic or electromagnetic systems. As such, the acceleration mechanism would need to be carefully designed in order to interact with a sufficient proportion of the charged species population. Since a magnetic acceleration mechanism has not yet been developed for such high propellant flows, no comment can presently be made about the amount of additional power required to achieve such performance and its subsequent influence on parameters such as the thrust efficiency. Parallel works at the institute are presently investigating the impact of DC magnets and magnetic novels on smaller-scale versions of the system presented here. The results of these works will be disseminated in future publications.

\subsection{CONCLUSION}

This paper has presented the experimental results of operating a preliminary inductive plasma thruster with alternative propellants. These results indicate that an inductive plasma thruster is compatible with a number of commonly-occurring gases $\left(\mathrm{O}_{2}, \mathrm{~N}_{2}, \mathrm{CO}_{2}\right)$ and that values of thrust and $\mathrm{I}_{s p}$ may be significantly increased (up to a factor of 3 in line with the current thruster configuration) by combining the chemical properties of the molecular propellants with an atomic gas, Ar. This combination is thought to take advantage of the low ionisation energy and high thermal conductivity of the monoatomic and polyatomic species, respectively, in order to increase the conversion of energy from the excitation mechanism to the propellant outflow. However, further investigation is needed to better understand the behaviour of the 
discharge volume. This investigation is presently underway and will be presented in subsequent publications. While the final values of $\mathrm{I}_{s p}$ presented in this paper are significantly lower than those achievable with conventional EP system, the lack of material degradation associated with inductive propulsion (when compared to direct-contact electrode systems) presents a distinct advantage. Furthermore, the geometry of the IPG7 may be further improved to increase the propellant acceleration. Modifications include the addition of a mechanical or magnetic nozzle or alterations to the discharge chamber geometry (to increase the maximum thermal efficiency of the system). Inductive propulsion systems hence have the potential to facilitate longer-duration, flexible-space operations without the reliance on Earth as the sole source of propellant in the solar system.

\section{ACKNOWLEDGEMENTS}

The authors of this paper would like to thank the Sir Ross and Sir Keith Smith Foundation and the German Research Foundation (DFG, Project HE 4563/3-1) for their financial contributions to personnel and equipment during this project.

\section{REFERENCES}

1. Mazanek, D. D., Merrill, R. G., Brophy, J. R. and Mueller, R. P. Asteroid redirect mission concept: A bold approach for utilizing space resources, Acta Astronautica, 2015, 117, pp 163-171, doi:10.1016/j.actaastro.2015.06.018

2. Anand, M., Crawford, I.A., Balat-Pichelin, M., Abanades S., van Westrenen, W., Peraudeau, G., Jaumann, R. and Seboldt W. A brief review of chemical and mineralogical resources on the moon and likely initial In Situ Resource Utilization (ISRU) applications, Planetary and Space Science, 2012, 74, pp 42-48, doi:10.1016/j.pss.2012.08.012

3. SANDERS, G. B. ISRU: An overview of NASA's current development activities and longterm goals, AIAA 38th Aerospace Sciences Meeting and Exhibit, 2000, Reno, NV, doi: $10.2514 / 6.2000-1062$

4. Frisbee, R. H., Polk, J. E., Gallimore, A. D. and Marrsee, C. M. Oxygen-propellant plasma thrusters for cis-lunar electric propulsion missions, 34th AIAA/ASME/SAE/ASEE Joint Propulsion Conference and Exhibit, 1998, Cleveland, doi:10.2514/6.1998-3994

5. Dressler, R. A., Chiu, Y. H. and Levandier, D. J. Propellant alternatives for ion and hall effect thrusters, AIAA 38th Aerospace Sciences Meeting and Exhibit, 2000, Reno, doi: $10.2514 / 6.2000-602$

6. Nishiyama, K. Air breathing ion engine concept, 54th International Astronautical Congress, 2003, Bremen, doi:10.2514/6.IAC-03-S.4.02

7. Cifali, G., Misuri, T., Rossetti, P., Andrenucci, M., Valentian, D., Feill, D. and Lotz, B. Experimental characterisation of HET and RIT with atmospheric propellants, 32nd International Electric Propulsion Conference, 2011, Wiesbaden, IEPC-2011-224.

8. Pekker, L. and KeIdar, M. Analysis of airbreathing hall effect thrusters, Journal of Propulsion and Power, 2012 28, (6), pp 1399-1405, doi: 10.2514/1.B34441

9. Hohman, K. Atmospheric Breathing Electric Thruster for Planetary Exploration, Final Report Grant no. NNX11AR29G, Busek Space Propulsion, 2012.

10. Shabshelowitz, A. Study of RF Plasma Technology Applied to Air-Breathing Electric Propulsion, PhD Thesis, University of Michigan, 2013.

11. Schoenherr, T., Komurasaki, K., Romano, F., Massuti-Ballester, B. and Herdrich, G. Analysis of atmosphere-breathing electric propulsion, IEEE Transactions on Plasma Science, 2015, 43, (1), pp 287-294, doi:10.1109/TPS.2014.2364053

12. Uematsu, K., Morimoto, S. and Kuriki, K. MPD thruster performance with various propellants, Journal of Spacecraft, 1984, 22, (4), pp 412-416, doi:10.2514/3.25766 
13. Hou, L., Shen, Y., TANG, H. and Zhao, W. Improvement on stability of water Arcjet, IEEE Transactions on Plasma Science, 2011, 39, (1), pp 608-614, doi:10.1109/TPS.2010.2088132

14. Shiraki, S., Fukutome, Y., Inoue, F., Matsumoto, K., Tahara, H., Nogawa, Y. and Momozawa, A. Performance characteristics of low-power Arcjet thruster systems with gas generators for water, 34th International Electric Propulsion Conference, 2015, Kobe, IEPC-2015-230.

15. Yanagida, N., Ohata, M., Horisawa, H. and Kobayashi, A. An Al-water Fed DC Arcjet, 34th International Electric Propulsion Conference, 2015, Kobe, IEPC-2015-232.

16. Charles, C., Boswell, R. W., Laine, R. and Maclellan, P. An experimental investigation of alternative propellants for the Helicon Double Layer Thruster, Journal of Physics D: Applied Physics, 2008, 41, pp 175-213, doi:10.1088/0022-3727/41/17/175213

17. Nguyen, S. V. T., Foster, J. E. and Gallimore, A. D. Operating a radio-frequency plasma source on water vapor, Review of Scientific Instruments, 2009, 80, pp 083503, doi:10.1063/1.3202250

18. Petro, E. M. and Sedwick, R. J. Effects of water-vapor propellant on electrodeless thruster performance, Journal of Propulsion and Power, 2017, 33, (6), pp 1410-1417, doi:10.2514/1.B36389

19. Linnell, J. A. and Gallimore, A. D. Efficiency analysis of a hall thruster operating with Krypton and Xenon, Journal of Propulsion and Power, 2006, 22, (6), pp 1402-1412, doi:10.2514/1.19613

20. Garrigues, L. Computational study of hall-effect thruster with ambient atmospheric gas as propellant, Journal of Propulsion and Power, 2012, 28, (2), pp 344-354, doi:10.2514/1.B34307

21. Singh, L. A. and WaLKer, M. L. R. A review of research in low earth orbit propellant collection, Progress in Aerospace Sciences, 2015, 75, pp 15-25, doi:10.2514/1.B34307

22. Kirtley, D., Slough, J., Pihl, C., Meier, E. and Milroy, R. Pulsed plasmoid propulsion: Airbreathing electromagnetic propulsion, IEPC, 2011, Wiesbaden, IEPC-2011-015.

23. Nishiyama, K. and Kuninaka, H. Discussion on performance history and operations of Hayabusa ion engines, Transactions of the Japan Society for Aeronautical and Space Sciences, Aerospace Technology Japan, 2012, 10, doi:10.2322/tastj.10.Tb_1

24. Gonzalez del Amo, J. A. Review of ESA Experimental Research Activities for Electric Propulsion, NATO Research and Technology Organisation - Technical Report, 2011.

25. Mercer, C.R., Mcguire, M. L., Oleson, S. R. and Barrett, M. J. Solar electric propulsion concepts for human space exploration, AIAA Space 2015, 2015, Cleveland, AIAA20154521.

26. Herdrich, G. and PetKow, D. High-enthalpy, water-cooled and thin-walled ICP source: characterization and MHD optimisation, Journal of Plasma Physics, 2008, 74, (3), pp 391-429.

27. Massuti-Ballester, B., Marynowski, T. and Herdrcih, G. New inductively heated plasma source IPG7, Frontier of Applied Plasma Technology, 2013, 6, (2).

28. Boenrk, H. For Inductive Re-heating of a Supersonic Plasma Flow (German), PhD Thesis, University of Stuttgart, 2009.

29. Romano, F., Herdrich, G., Binder, T., Boxberger, A., Traub, C., Fasoulas, S., Schnherr, T and RoBERTS, P. Effects of applied magnetic field on IPG6-S, test-bed for an ABEP-based Inductive Plasma Thruster (IPT), Space Propulsion, 2018, Seville, SP2018 00412.

30. Chadwick, A. R., Herdrich, G., Kim, M. and Dally, B. Transient electromagnetic behaviour in inductive oxygen and argon-oxygen plasmas, Plasma Sources Science and Technology, 2016, 25, (6), doi:10.1088/0963-0252/25/6/065025

31. Fritz Duesseldorf GmbH. Technical Specification of the RF-Capacitors and the Triode RS 3300 CJ of the PWK3-IPG Energy Supply (German), Technical Report, 1997.

32. BARnetT, J. J. and ChANDRA, S. COSPAR International Reference Atmosphere, Technical Report, Committee on Space Research, 2012.

33. Yelle, R. V., Strobell, D. F., Lellouch, E. and Gautier, D. Engineering models for Titan's atmosphere, Huygens: Science, Payload and Mission, ESA Special Publication, 1997, 1177, pp 243-256.

34. Liang, M. C., Lane, B. F. Pappalardo, R. T., Allen, M. and Yung, Y. L. Atmosphere of Callisto, Journal of Geophysical Research, 2005, 110, doi:10.1029/2004JE002322

35. Shematovich, V. I., Johnson, R. E., Cooper, J. F. and Wong, M. C. Surface-bound atmosphere of Europa, Icarus, 2005, 173, pp 480-498, doi:10.1016/j.icarus.2004.08.013

36. Accettura, A. G., Bruno, C., Casotto, S. and Marzari, F. Mission to mars using integrated propulsion concepts: Considerations, opportunities, and strategies, Acta Astronautica, 2005, 54, (7), pp 471-486, doi:10.1016/S0094-5765(03)00208-X 
37. McElroy, M. B., Kong, T. Y. and Yung, Y. L. Photochemistry and evolution of Mars' atmosphere: A viking perspective, Journal of Geophysical Research, 1977, 82, (28), pp 4379-4388, doi:10.1029/JS082i028p04379

38. Hunten, D. M., Colin, L., Donahue, T. M. and Moroz, V. I. (Eds), Venus, University of Arizona Press, Tuscon, 1983.

39. Linstrom, P. J. and Mallard, W. G. (Eds), NIST Chemistry WebBook, NIST Standard Reference Database Number 69, National Institute of Standards and Technology, Gaithersburg, 2017, doi:10.18434/T4D303

40. Cottrell, T. L. The Strengths of Chemical Bonds, London, 2nd ed., 1958.

41. DARWENT, B. NIST Reference Data Series Number 31, National Bureau of Standards, Washington, 1970.

42. Benson, S. W. III - Bond Energies, Journal of Chemical Education, 1965, 42, (9), pp 502, doi:10.1021/ed042p502

43. Kerr, J. A. Bond dissociation energies by kinetic methods, Chemical Review, 1966, 66, (5), pp 465-500, doi:10.1021/cr60243a001

44. Lieberman, M. and Lichtenberg, A. Principles of plasma discharges and materials processing, John Wiley and Sons Inc., Hoboken, 2nd ed., 2005.

45. Sleziona, C. High Enthalpy Flows for Space Applications (German), PhD Thesis, University of Stuttgart, 1998.

46. LenzNer, S. Numerical Analysis of Flow Phenomena in an Inductive Heated Plasma Sources (German), PhD Thesis, University of Stuttgart, 2000.

\section{APPENDIX}

Table 5

Chemical properties and reaction data for the species considered in this work ${ }^{(39,40,41,42,43)}$

$\begin{array}{lcccccc} & \begin{array}{c}\mathbf{M} \\ {[\mathbf{k g} / \mathbf{m o l}]}\end{array} & \begin{array}{c}\boldsymbol{\rho}_{\mathbf{2 9 8 K}} \\ {\left[\mathbf{k g} / \mathbf{m}^{\mathbf{3}}\right]}\end{array} & \begin{array}{c}\mathbf{c}_{\boldsymbol{p}, \mathbf{2 9 8 K}} \\ {[\mathbf{k J} / \mathbf{k g} . \mathbf{K}]}\end{array} & \begin{array}{c}\boldsymbol{\kappa}_{\mathbf{2 9 8 K}} \\ {[\mathbf{k W} / \mathbf{m} . \mathbf{K}]}\end{array} & \begin{array}{c}\boldsymbol{\Delta} \boldsymbol{H}_{\boldsymbol{f}, \mathbf{2 9 8 K}} \\ {[\mathbf{k J J} / \mathbf{m o l}]}\end{array} & \begin{array}{c}\boldsymbol{\Delta} \boldsymbol{H}_{\boldsymbol{i}, \mathbf{2 9 8} \boldsymbol{K}} \\ {[\mathbf{k J} / \mathbf{m o l}]}\end{array} \\ \mathrm{Ar} & 40 \times 10^{-3} & 1.784 & 0.520 & 1.835 \times 10^{-5} & - & 1521 \\ \mathrm{O}_{2} & 32 \times 10^{-3} & 1.429 & 0.919 & 2.736 \times 10^{-5} & \mathrm{O}=\mathrm{O}, 498.3 & 1165 \\ \mathrm{O} & 16 \times 10^{-3} & - & - & - & - & 1314 \\ \mathrm{~N}_{2} & 28 \times 10^{-3} & 1.250 & 1.040 & 2.703 \times 10^{-5} & \mathrm{~N} \equiv \mathrm{N}, 946.0 & 1503 \\ \mathrm{~N} & 14 \times 10^{-3} & - & - & - & - & 1402 \\ \mathrm{CO}_{2} & 44 \times 10^{-3} & 1.977 & 0.844 & 1.771 \times 10^{-5} & \mathrm{C}=\mathrm{O}, 749.0 & 1329 \\ \mathrm{CO} & 28 \times 10^{-3} & 1.250 & 1.043 & 2.722 \times 10^{-5} & \mathrm{C}=\mathrm{O}, 749.0 & 1352 \\ \mathrm{C} & 12 \times 10^{-3} & - & - & - & - & 1086\end{array}$


Table 6

Propellant flow rates tested

\begin{tabular}{|c|c|c|c|c|c|c|c|c|c|c|c|c|}
\hline & $\begin{array}{c}\dot{V}_{A r} \\
{\left[\mathbf{l}_{n} / \mathbf{m i n}\right]}\end{array}$ & $\begin{array}{l}\dot{\boldsymbol{m}}_{A r} \\
{[\mathrm{~g} / \mathrm{s}]}\end{array}$ & $\begin{array}{c}\dot{\boldsymbol{V}}_{\boldsymbol{o}_{\mathbf{2}}} \\
{\left[\mathbf{I}_{n} / \mathbf{m i n}\right]}\end{array}$ & $\begin{array}{l}\dot{\boldsymbol{m}}_{\mathrm{O}_{2}} \\
{[\mathrm{~g} / \mathrm{s}]}\end{array}$ & $\begin{array}{c}\dot{\boldsymbol{V}}_{\mathrm{N}_{\mathbf{2}}} \\
{\left[\mathrm{I}_{n} / \mathrm{min}\right]}\end{array}$ & $\begin{array}{l}\dot{m}_{N_{2}} \\
{[\mathrm{~g} / \mathrm{s}]}\end{array}$ & $\begin{array}{c}\dot{\boldsymbol{V}}_{\mathrm{CO}_{2}} \\
{\left[\mathbf{l}_{n} / \mathrm{min}\right]}\end{array}$ & $\begin{array}{r}\dot{\boldsymbol{m}}_{\mathrm{CO}_{2}} \\
{[\mathrm{~g} / \mathrm{s}]}\end{array}$ & $\begin{array}{l}\dot{\boldsymbol{m}}_{e f f} \\
{[\mathrm{~g} / \mathrm{s}]}\end{array}$ & $\left.\underset{\left[\times 10^{24}\right.}{\mathbf{j}} 1 / \mathrm{s}\right]$ & $\mathbf{X}_{A r}$ & $\mathbf{X}_{x}$ \\
\hline 1 & 100 & 2.97 & - & - & - & - & - & - & 2.97 & 2.69 & 1.0 & - \\
\hline 2 & 67 & 1.99 & - & - & - & - & - & - & 1.99 & 1.80 & 1.0 & - \\
\hline 3 & 50 & 1.49 & - & - & - & - & - & - & 1.49 & 1.34 & 1.0 & - \\
\hline 4 & - & - & 105 & 2.50 & - & - & - & - & 2.50 & 2.82 & - & 1.0 \\
\hline 5 & 75 & 2.23 & 53 & 1.26 & - & - & - & - & 3.49 & 3.44 & 0.59 & 0.41 \\
\hline 6 & 90 & 2.68 & 43 & 1.01 & - & - & - & - & 3.69 & 3.56 & 0.68 & 0.32 \\
\hline 7 & - & - & - & - & 107 & 2.23 & - & - & 2.23 & 2.88 & - & 1.0 \\
\hline 8 & 67 & 1.99 & - & - & 41 & 0.85 & - & - & 2.85 & 2.90 & 0.62 & 0.38 \\
\hline 9 & 75 & 2.23 & - & - & 54 & 1.13 & - & - & 3.36 & 3.47 & 0.58 & 0.42 \\
\hline 10 & 90 & 2.68 & - & - & 43 & 0.90 & - & - & 3.58 & 3.57 & 0.68 & 0.32 \\
\hline 11 & 100 & 2.97 & - & - & 36 & 0.75 & - & - & 3.72 & 3.65 & 0.74 & 0.26 \\
\hline 12 & - & - & - & - & - & - & 80 & 2.64 & 2.64 & 2.16 & - & 1.0 \\
\hline 13 & - & - & - & - & - & - & 53 & 1.76 & 1.76 & 1.44 & - & 1.0 \\
\hline 14 & 90 & 2.68 & - & - & - & - & 32 & 1.05 & 3.73 & 3.28 & 0.74 & 0.26 \\
\hline 15 & 100 & 2.97 & - & - & - & - & 27 & 0.89 & 3.86 & 3.42 & 0.79 & 0.21 \\
\hline
\end{tabular}

